\section{Upper mantle model variations}

from our Geomagnetism Correspondent

As the newly-formed oceanic lithosphere spreads away from its ridge source it gradually cools and contracts; and the elevated, rugged topography characteristic of the ridge ultimately gives way to the lower, smoother surface beneath the sediments of the ocean basin. If the cooling, contracting lithosphere were to move over a laterally uniform asthenosphere, the only other factor governing the ridge shape and dimensions would be the spreading rate. Thus several workers, beginning with McKenzie ( $J$. geophys. Res., 72, 6261; 1967), have constructed thermal models involving the structure of the lithosphere across ocean ridges in which particular attention has been paid to the effect of spreading rate on the topographic profile. In all such models the spreading rate was found to affect principally the horizontal scale of the topography, with an increase in spreading rate producing a lengthened section but almost no variation in vertical dimensions. But as Haigh (Geophys. J., 33, 405 ; 1973) has now pointed out with reference to the North Atlantic, although the differences in horizontal scale predicted by previous thermal models exist, there are also variations of ridge and basin structure with latitude which cannot be attributed to differences in spreading rate. He thus concludes that the basic premise of a uniform asthenosphere is wrong, and that instead the temperature at a given depth in the asthenosphere must vary laterally.

The latitudinal variations which require explanation have been known in general terms for some time, the particular data now analysed by Haigh being derived from Atlantic bathymetric and gravimetric profiles obtained as long ago as 1964-1965. From these it is clear, for example, that between low latitudes and Iceland the depth at which the topographic profiles across the Atlantic ridge system become level in the ocean basins decreases northwards from $5.5 \mathrm{~km}$ at $30^{\circ} \mathrm{N}$ to $3.0 \mathrm{~km}$ and $60^{\circ} \mathrm{N}$. Because the ocean basin level is not reached at the same distance from the ridge throughout the whole latitude range, there may be a suspicion that the variation of basin depth with latitude arises from differences in lithospheric age. No such explanation is possible here, however, because all the ages involved are greater than 60 million years; and as Sclater et al. (J.geophys. Res., 76, 7888; 1971) have shown, changes in clevation beyond this age are negligible. Nor can the marked northward decrease in basin to ridge crest elevation between the Azores and Iceland (the region studied in detail by Haigh) be explained away quite so simply. On the other hand, spreading effects are significant when it comes to ridge cross-sectional area. Even so, when the effects of variable spreading rate on horizontal scale are adjusted throughout to the spreading rate at $43^{\circ} \mathrm{N}$, there is still found to be a marked decrease in ridge cross-section area northwards from the Azores.

To investigate the causes of these variations Haigh has constructed a model in which, in common with previous thermal models, the lithosphere is regarded as a slab of uniform thickness resting isostatically on an asthenosphere assumed to be at constant temperature across the ridge. As new material at this temperature is added gradually to one end of the slab, the slab increases in length so that a point on the lithosphere moves away from the hot edge at a rate governed by the rate at which new material is added. Solution of the relevant differential equations in conjunction with assumed values of the physical parameters involved then gives the temperature distribution in the lithospheric slab for any given slab thickness and composition. But in order to obtain an clevation profile from the temperature distribution it is necessary to know the density of the lithospheric material at the appropriate temperatures and pressures-and this involves all the usual problems in dealing with a body whose composition is unobtainable by direct sampling.

Haigh's approach has been to asssume that the upper mantle comprises basalt and dunite, with or without water, and either in the ratio 1:3 as suggested by Ringwood (J. geophys. Res., 67, 857; 1962) in his 'pyrolite' model or in the ratio 1:1 as proposed by Press (Science, N.Y. 165, 174; 1969). The end result is then a series of calculated ocean ridge profiles (elevation-distance graphs out to $900 \mathrm{~km}$ form the ridge) for the two different basalt-dunite compositions, with or without the involvement of water, and for various lithospheric thicknesses. In addition, to account for possible heat transfer by radiation, a futher variable in the form of a conductivity increase above $800^{\circ} \mathrm{C}$ has been introduced.

The general conclusion derived from a comparison of the calculated and observed profiles was that many models give too great a ridge elevation unless the allowed ranges of lithospheric thickness and composition are limited. More specifically, a composition involving a basalt-dunite ratio of 1:3 was found to be more likely than one with a ratio of $1: 1$; and the mantle must contain a small amount of water in order to allow the decoupling between the lithosphere and asthenosphere to occur at a lower temperature than is necessary for a dry model. In addition, models involving a conductivity increase above $800^{\circ} \mathrm{C}$ were in poor agreement with observation, having too much elevation at the ridge axis and not enough on the flanks. And, finally, raised temperatures in the asthenosphere were found to give an upward migration of phase boundaries, resulting in a thinner lithosphere and thus a reduction of ridge cross section and elevation.

In the context of the observed variations with latitude between the Azores and Iceland the last of these conclusions is particularly significant, for it implies an explanation. Haigh's next step was thus to compare the North Atlantic topographic profiles with profiles calculated for a range of lithospheric thicknesses. From a least squares fit between each observed profile and the calculated profiles with different thicknesses, it became clear that the lithosphere thins from $85 \mathrm{~km}$ at $43^{\circ} \mathrm{N}$ to $64 \mathrm{~km}$ at $61^{\circ} \mathrm{N}$ (although these thicknesses increase by about $10 \mathrm{~km}$ on average if the presence of sediments is taken into account). In view of the conclusion that a thinned lithosphere is associated with raised temperatures in the asthenosphere, Haigh thus suggests that the temperature at a given depth in the asthenosphere gradually increases northwards from the Azores to Iceland. $\mathrm{He}$ is also able to show that such a lateral temperature variation in both the asthenosphere and lithosphere can explain the northward rise of the whole basin and ridge system with respect to sea level, and not just the variation of those parameters such as ridge cross section and elevation which are measured with respect to the ocean basin level.

In thinking about a northward temperature increase towards Iceland it is tempting to see Iceland as the region of maximum temperature and thus as either the site of an uprising mantle plume as suggested by Morgan (Nature, 230, 42; 1971) or of a convective overturn as suggested by Bott (in Implications of Continental Drift to the Earth Sciences, Academic Press, 1973). If Iceland really is the temperature focus, the northward variations between the Azores and Iceland should be mirrored by similar variations southward between the Aretic and Iceland. At present there are few data from north of Iceland, and so little can be said about this except that Haigh claims some support for the dimensional increase in the ridge to the north in the work of Johnson and Heezen (Deep-Sea Res., 14, 755; 1967). For the time being, Haigh is obviously unwilling to be drawn into a detailed argument over mantle plumes, and rests content with the comment that his model is consistent with uniquely higher temperatures beneath Iceland. But he cmphasises that his general conclusions, if valid, should be applicable to other ridge systems. 